\title{
SISTEM PENGENDALI PENAMPUNGAN AIR DALAM RUMAH TANGGA DENGAN MENGGUNAKAN MIKROKONTROLLER AT89S51
}

\author{
Abdurahman \\ Program Studi Informatika, Universitas Indraprasta PGRI \\ abdjur97@gmail.com
}

\begin{abstract}
Abstrak
Sistem yang berjalan secara otomatis sekarang ini semakin digemari. Salah satu contohnya pengisian air di penampungan air rumah kita. Penampungan air saat ini baru berjalan secara otomatis hanya sistem pengisiannya saja. Untuk sistem pengurasan masih menggunakan sistem manual. Tujuan dari penampungan air baik sistem pengisian maupun pengurasan bekerja secara otomatis agar kualitas air yang digunakan dapat lebih bersih. Hal ini dapat bermanfaat untuk kesehatan. Metode yang digunakan yaitu dengan melihat kerja penampungan air yang digunakan saat ini untuk melihat kekurangan dalam sistem otomatisnya. Setelah itu merancang dan merakit alat agar mendapatkan hasil yang kita inginkan yaitu penampungan air bekerja secara otomatis baik sistem pengisian maupun sistem pengurasan. Perancangan sistem alat ini menggunakan LDR sebagai input yang berfungsi untuk menjalankan rangkaian mikrokontroller sehingga menghasilkan output.
\end{abstract}

Kata Kunci : Penampungan air, sistem otomatis, LDR

\begin{abstract}
The automatic systems are now getting more popular. One of them is the filling system of water tank in our house. Even so, the current water tank runs automatically only for its filling system. It still uses manual system for its drainage system. In fact, the automatic filling and drainage water tank systems can be used to provide cleaner water that can be beneficial for health. The method used is looking at the working of water tank currently used to see the deficiencies in its automatic system. Then, designing and assembling a tool to get an expected result, namely the water tank system working automatically, both its filling system and drainage system. The design of this tool system uses LDR as input to run the microcontroller circuit to produce output.
\end{abstract}

Keywords: Water reservoir, automatic system, $L D R$

\section{PENDAHULUAN}

Sekarang ini sistem yang bekerja secara otomatis sangat digemari, karena alat ini dapat menggantikan fungsi manusia untuk mengerjakan suatu sistem. Salah satu contohnya sistem pada penampungan air di rumah kita. Saat ini sistem otomatis yang dijalankan di penampungan air hanya pada sistem pengisian saja, untuk sistem pengurasan masih menggunakan sistem manual yaitu dengan tenaga manusia. Untuk itu kita mencoba untuk merancang sistem penampungan air yang bekerja secara otomatis baik pada sistem pengisian air maupun sistem pengurasan. Tujuan dari perancangan alat ini untuk menggantikan tenaga manusia pada sistem pengurasan. Penampungan air yang memiliki sistem pengisian maupun sistem pengurasan bekerja secara otomatis dapat memberi manfaat kebersihan air yang lebih baik. Berdasarkan hal di atas maka saya mencoba mengambil judul "Sistem Pengendali Penampungan Air pada Rumah Tangga dengan Menggunakan Mikrokontroller AT89S51. Rangkaiannya terdiri dari lima bagian, diantaranya adalah rangkaian satu daya, rangkaian input, rangkaian mikrokontroler, rangkaian output. Input yang digunakan untuk mengatur kerja alat tersebut adalah cahaya 
dari pointer. Apabila LDR terkena cahaya maka hambatan LDR akan kecil sehingga transistor akan cut off, hal ini menyebabkan mikrokontroler tidak bekerja sehingga output tidak dihasilkan. Sebaliknya apabila LDR tidak terkena cahaya maka nilai hambatannya menjadi besar sehingga transistor akan saturasi. Hal ini menyebabkan bekerjanya mikrokontroler sehingga menghasilkan output sesuai dengan program yang dibuat menggunakan READs51. Rangkaian ini bekerja menggunakan tiga sensor LDR yang digunakan untuk menjalankan pompa 1 untuk pengisian air, pompa 2 untuk membuang air, solenoid valve untuk memberi cairan pembersih saat sistem pembersih penampungan air sedang bekerja, LED 1 untuk mengetahui level air, LED 2 untuk mengetahui berapa kali pengisian air pada penampungan air. Rangkaian tersebut memiliki persyaratan penampungan air terbuat dari akrilik bening.

Terdapat beberapa komponen yang digunakan di dalam pembuatan rangkaian pengendali penampungan air, diantaranya adalah :

\section{A. Resistor}

Resistor bersifat menghambat arus listrik yang melewatinya. Resistor terdiri dari beberapa jenis, diantaranya resistor nilainya tetap, resistor nilainya tidak tetap, dan resistror nilainya tergantung dari cahaya (LDR).

1) LDR (Light Dependent Resistor)

LDR adalah komponen yang hambatannya berubah-ubah tergantung dari cahaya yang diterima di permukaannya[1]. Apabila cahaya diterima mengecil maka hambatan membesar. Apabila kita lihat dalam sebuah LED , maka LED akan menyala bila cahaya meredup, sebaliknya
LED meredup bila cahaya terang diterima LDR[1].

LDR digunakan sebagai pembagi tegangan[3].

2) Pembagi tegangan dengan resistor Pembagi tegangan dengan resistor sering kita gunakan dalam rangkaian. Salah satu fungsinya adalah untuk menurunkan tegangan [1]. Kita dapat memperoleh tegangan keluarannya (Vout) [1] :

$$
\text { Vout }=\frac{\mathrm{R}_{2}}{\mathrm{R}_{1}+\mathrm{R}_{2}}\left(\mathrm{~V}_{\text {in }}\right)
$$

\section{B. Transistor sebagai saklar}

Bila Vi bertegangan $<0,5 \mathrm{~V}$ sambungan emitter-Base akan terbias balik sehingga hanya arus yang sangat kecil melaluinya dan transistor bekerja CUTOFF [5].

Arus yang signifikan baru akan dapat mengalir bila Vi > 0,7 V [5]. Dalam hal ini arus basis adalah :

$$
\begin{aligned}
& \mathrm{i}_{\mathrm{B}}=\frac{\mathrm{Vi}-\mathrm{V}_{\mathrm{BE}}}{\mathrm{R}_{\mathrm{B}}} \approx \frac{\mathrm{V}_{\mathrm{i}}-0.7}{\mathrm{R}_{\mathrm{B}}} \\
& \mathrm{i}_{\mathrm{C}}=\beta . \mathrm{i}_{\mathrm{B}}
\end{aligned}
$$

\section{Mikrokontroller}

IC AT89C51 adalah rangkaian mikrokontroller yang kompatibel dengan keluarga IC 80C51. Selain 89C51 yang memiliki momori internal $4 \mathrm{~K}$ juga terdapat tipe diatasnya yang memiliki kemasan sama tapi berbeda dalam kapasitas memori, yaitu 89C52 memiliki 8K, 89C54 memiliki 16K dan 89C58 memiliki 32K. Operasi mikrokontroller dapat diprogram dengan bahasa assembly maupun bahasa $\mathrm{C}$ [7].

1). Konfigurasi Pin dari AT89S51

Didalam mikrokontroller

AT89S51 memiliki 40 pin dimana tiap pin mempunyai fungsi 
masing-masing. Pin IC mikrokontroller dapat dilihat pada gambar 1 .

\begin{tabular}{|c|c|c|c|c|}
\hline & P1.0 & 1 & 40 & $\square$ Vcc \\
\hline & P1.1 ᄂ & 2 & 39 & $\dashv P 0.0(A D 0)$ \\
\hline & P1.2 & 3 & 38 & $\square P 0.1 \quad(\mathrm{AD} 1)$ \\
\hline & P1.3 & 4 & 37 & $\square P 0.2(\mathrm{AD} 2)$ \\
\hline & P1.4 ᄃ & 5 & 36 & $\square$ P0.3 (AD3) \\
\hline & P1.5 & 6 & 35 & P 0.4 (AD4) \\
\hline & P1.6 & 7 & 34 & $\square$ P0.5 (AD5) \\
\hline & P1.7 ᄂ & 8 & 33 & $\dashv \mathrm{P} 0.6 \quad(\mathrm{AD} 6)$ \\
\hline & RST & 9 & 32 & 口P0.7 (AD7) \\
\hline$(R \times D)$ & P3.0 & 10 & 31 & $\square \overline{E A} / V P P$ \\
\hline$(T \times D)$ & P3.1 प & 11 & 30 & $\square A L E / \overline{P R O G}$ \\
\hline$(\overline{\mathrm{INTO}})$ & P3.2 口 & 12 & 29 & $\square \overline{\mathrm{PSEN}}$ \\
\hline (INT1) & P3.3 & 13 & 28 & $\square$ P2.7 (A15) \\
\hline (TO) & P3.4 L & 14 & 27 & $\neg$ P2.6 (A14) \\
\hline (T 1) & P3.5 & 15 & 26 & $\square$ P2.5 (A13) \\
\hline$(\overline{W R})$ & P3.6L & 16 & 25 & $\longrightarrow$ P2.4 (A12) \\
\hline$(\overline{R D})$ & P3.7 & 17 & 24 & $\square^{2} 2.3(\mathrm{~A} 11)$ \\
\hline & XTAL 2 & 18 & 23 & $\square$ P2.2 (A10) \\
\hline & XTAL 1 - & 19 & 22 & $\square$ P2.1 (A9) \\
\hline & GND & 20 & 21 & $\neg P 2.0(\mathrm{~A} 8)$ \\
\hline
\end{tabular}

Gambar 1. Pin IC mikrokontroller

Kegunaan masing-masing pin[6] :

- Port 1 sebagai I/O

- RST sebagai input untuk reset terhadap mikro

- Port 3 sebagai I/O atau dapat berfungsi lainnya.

- XTAL 1 dan XTAL 2 sebagai pin inputan untuk kristal osilator.

- GND sebagai ground

- Port 2 sebagai I/O.

- PSEN adalah pulsa pengaktif untuk membaca program memori luar.

- ALE berfungsi sebagai demultiplexer pada saan port 0 bekerja sebagai pengakses memori eksternal.

- EA harus dihubungkan dengan ground apabila menggunakan program memori luar.

- Port 0 sebagai I/O

- VCC sebagai sumber tegangan sebesar $5 \mathrm{~V}$.
D. Relay

Transistor tidak dapat berfungsi sebagai saklar tegangan tinggi. Selain itu transistor umumnya tidak digunakan sebagai switching untuk arus besar (> 5A) [4]. Relay adalah sebuah saklar elektromagnetik yang prinsip kerjanya menggunakan asas kumparan listrik. Di dalam rangkaian elektronik relay digunakan sebagai saklar yang bekerja secara otomatis, sehingga kita dapat mengatur nyala suatu rangkaian elektronik walaupun kita tidak berada di tempat tersebut.

\section{E. Light Emitting Diode (LED)}

LED adalah komponen yang memancarkan cahaya apabila kaki yang disebut anode dan kaki yang disebut katode terhubung negatif. Pada LED nyata kaki yang lebih panjang adalah anode [2].

\section{METODE PENELITIAN}

Didalam merancang sistem pengendalian penampungan air dengan menggunakan mikrokontroler telah dilakukan berbagai tahapan penelitian diantaranya adalah, menganalisa masalah, studi kasus, merancang sistem. Menganalisa masalah dengan melihat sistem kerja dari penampungan air yang ada. Setelah Mencari solusi didalam kelemahan system penampungan air yang ada saat ini. Setelah itu melakukan perancangan sistem baik rangkaian input, mikrokontroller maupun output. Setelah masing-masing rangkaian sudah dirancang lalu dibuat dalam bentuk PCB untuk melihat kerja masing-masing rangkaian. Setelah itu baru kita buat program mikrokontroller untuk menjalankan sistem penampungan air yang kita buat. 


\section{HASIL DAN PEMBAHASAN}

Dalam merancang sistem yang baik diperlukan langkah-langkah yaitu merancang blok diagram sistem, merancang flow chart, merancang perangkat keras dan merancang perangkat lunak.

\section{A. Merancang Blok Diagram}

Tahap awal dari perancangan sistem adalah merancang blok diagram dari system yang akan dibuat. Blok diagram sistem pengendali penampungan air dalam rumah tangga dengan menggunakan mikrokontroller.

\section{B. Merancang Flow Chart}

Flow chart dari sistem pengendali penampungan air dalam rumah tangga dengan menggunakan mikrokontroler dapat kita lihat pada gambar 3. dibawah ini :

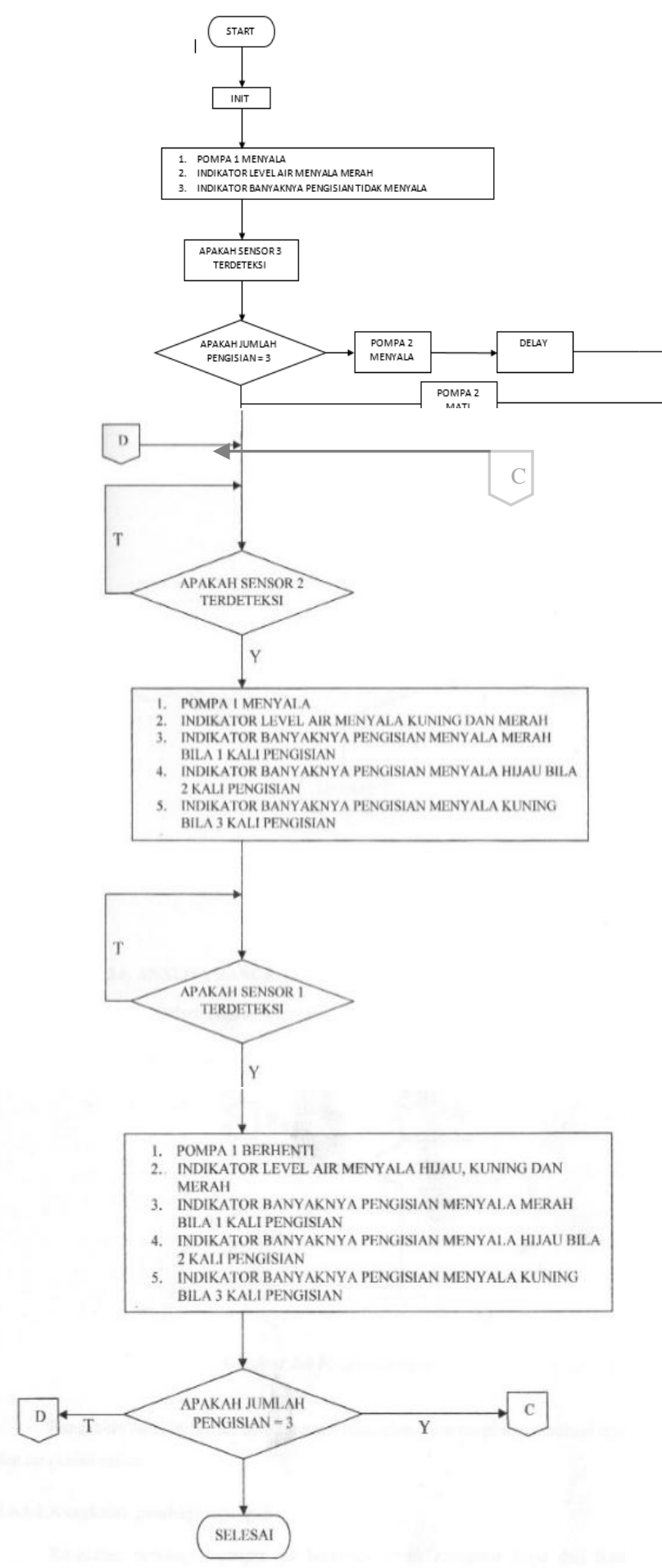

Gambar 2. Flow chart
C. Perancangan Perangkat Lunak

Dalam sistem tersebut perangkat elektronik yang akan dirancang adalah 
rangkaian catu daya, rangkaian output, rangkaian mikrokontroler, rangkaian indikator LED 1, rangkaian indicator LED 2, rangkaian output pompa 1, rangkaian output pompa 2, rangkaian solenoid valve.

1). Rangkaian catu daya

Rangkaian catu daya merupakan rangkaian pemberi tegangan bagi rangkaian keseluruhan agar rangkaian dapat berjalan. Tegangan yang digunakan untuk rangkaian ini adalah $5 \mathrm{~V}$ dan $12 \mathrm{~V}$. Rangkaian ini terdiri dari transformator step down, diode bridge, Ic regulator 7805 dan 7812 , resistor $470 \Omega$ dan LED. Untuk lebih jelasnya rangkaian catu daya dapat dilihat pada gambar 3 dibawah ini :

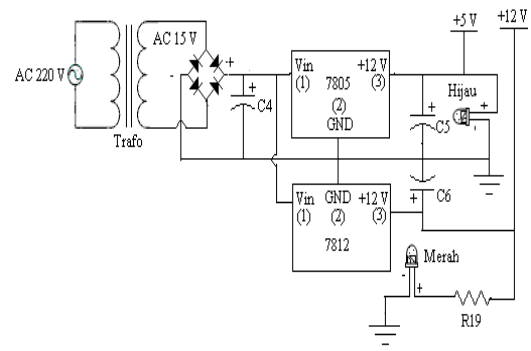

Gambar 3. Rangkaian catu daya

2). Rangkaian input

Rangkaian input pada rangkaian ini berfungsi untuk memberikan input pada mikrokontroler agar mikrokontroler dapat mengetahui tindakan apa yang harus dikerjakan untuk dijadikan output. Rangkaian input dapat kita lihat pada gambar 4 dibawah ini :

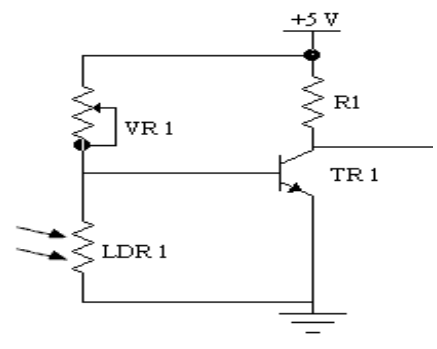

Gambar 4. Gambar rangkaian input
Rangkaian input terdiri dari dua rangkaian, yaitu rangkaian pembagi tegangan dan rangkaian transistor sebagai saklar.

a). Rangkaian pembagi tegangan

Rangkaian pembagi tegangan dapat kita lihat pada gambar 5 dibawah ini

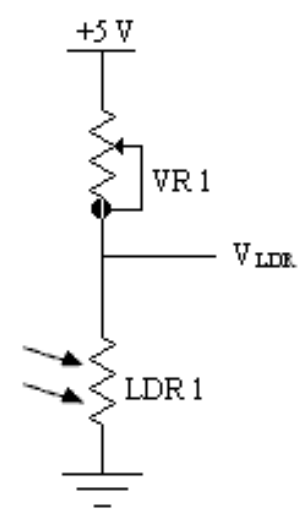

Gambar 5. Pembagi Tegangan Rumus pada rangkaian pembagi tegangan adalah

$$
\begin{aligned}
R p & =\frac{R_{L D R} \cdot R_{V}}{R_{L D R}+R_{V}} \\
V_{B B}= & \frac{R_{L D R} \cdot V_{C C}}{R_{L D R}+R_{V}}
\end{aligned}
$$

Bila $\mathrm{Rv} 15.5 \mathrm{k} \Omega$ Sehingga diperoleh hasil :

- LDR tidak terkena cahaya $(\mathrm{RLDR}=158 \mathrm{k} \Omega)$

$\mathrm{Rp}=\frac{158.15 .5}{158+15.5}$

$\mathrm{Rp}=14.11 \mathrm{k} \Omega$

$\mathrm{V}_{\mathrm{BB}}=\frac{158(5 \mathrm{~V})}{158+15.5}$

$\mathrm{V}_{\mathrm{BB}}=4.55 \mathrm{~V}$

- $\mathrm{LDR}$ terkena cahaya $\left(\mathrm{R}_{\mathrm{LDR}}=\right.$ $320 \Omega$ )

$\mathrm{Rp}=\frac{320 \Omega .15 .5 \mathrm{k} \Omega}{320 \Omega+15.5 \mathrm{k} \Omega}$ 


$$
\begin{aligned}
& \mathrm{Rp}=0.31 \mathrm{k} \Omega \\
& \mathrm{V}_{\mathrm{BB}}=\frac{320 \Omega(5 \mathrm{~V})}{320 \Omega+15.5 \mathrm{k} \Omega} \\
& \mathrm{V}_{\mathrm{BB}}=0.10 \mathrm{~V}
\end{aligned}
$$

b). Rangkaian transistor sebagai saklar. Rangkaian transistor sebagai saklar dapat dilihat pada gambar 6 dibawah ini :

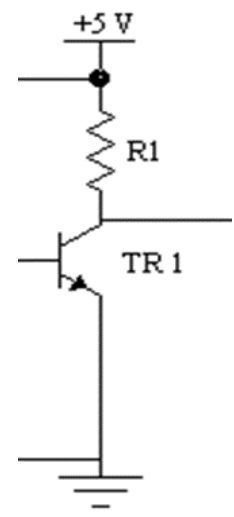

\section{Gambar 6. rangkaian transistor} sebagai saklar

$$
\mathrm{V}_{\mathrm{CC}}=\mathrm{I}_{\mathrm{C}} \cdot \mathrm{R}_{\mathrm{C}}+\mathrm{V}_{\mathrm{CE}}
$$

Mencari $\mathrm{V}_{\mathrm{CE}}$ cutoff maka

$\mathrm{I}_{\mathrm{C}}=0$, sehingga

$\mathrm{V}_{\mathrm{CC}}=\mathrm{V}_{\mathrm{CE}}$ cut off

$\mathrm{V}_{\mathrm{CE}}$ cut off $=5 \mathrm{~V}$

Mencari $\mathrm{I}_{\mathrm{C}}$ saturasi maka $\mathrm{V}_{\mathrm{CE}}=0$

$\mathrm{V}$, sehingga

$\mathrm{I}_{\mathrm{C}}$ sat $=\mathrm{V}_{\mathrm{CC}} / \mathrm{R}_{\mathrm{C}}$

$$
\begin{aligned}
& =5 \mathrm{~V} / 10 \mathrm{k} \Omega \\
& =0.5 \mathrm{~mA}
\end{aligned}
$$

Analisa rangkaian saklar :

Untuk $\mathrm{Rv}=15.5 \mathrm{k}$ dan kondisi LDR adalah :

a. LDR tidak terkena cahaya $\mathrm{R}_{\mathrm{LDR}}=$ $158 \mathrm{k} \Omega$

$$
\begin{aligned}
& \mathrm{R}_{\mathrm{P}}=14.11 \mathrm{k} \Omega \\
& \mathrm{V}_{\mathrm{BB}}=4.55 \mathrm{~V} \\
& \text { Maka nilai } \mathrm{I}_{\mathrm{B}} \text { adalah : } \\
& \mathrm{I}_{\mathrm{B}}=\frac{\mathrm{V}_{\mathrm{BB}}-0,7 \mathrm{~V}}{\mathrm{R}_{\mathrm{B}}}
\end{aligned}
$$

$$
\begin{aligned}
& \mathrm{I}_{\mathrm{B}}=\frac{4.55 \mathrm{~V}-0.7 \mathrm{~V}}{14.11 \mathrm{k} \Omega} \\
& \mathrm{I}_{\mathrm{B}}=0.27 \mathrm{~mA}
\end{aligned}
$$

Sehingga nilai $\mathrm{I}_{\mathrm{C}}$ adalah:

$$
\begin{aligned}
\mathrm{I}_{\mathrm{C}} & =\beta \cdot \mathrm{I}_{\mathrm{B}} \\
& =110 \cdot 0,43 \mathrm{~mA} \\
& =29 \cdot 7 \mathrm{~mA}
\end{aligned}
$$

Maka transistor saturasi, karena $\mathrm{I}_{\mathrm{C}}>\mathrm{I}_{\mathrm{C}}$ saturasi

b. LDR terkena cahaya :

$$
\mathrm{R}_{\mathrm{P}}=0.31 \mathrm{k} \Omega
$$$$
\mathrm{V}_{\mathrm{BB}}=0.10 \mathrm{~V}
$$

Maka nilai $\mathrm{I}_{\mathrm{B}}$ adalah :

$$
\begin{aligned}
I_{B} & =\frac{V_{B B}-0,7 V}{R_{B}} \\
I_{B} & =\frac{0.1 \mathrm{~V}-0.7 \mathrm{~V}}{0.31 \mathrm{k} \Omega} \\
I_{B} & =-1,93 \mathrm{~mA}
\end{aligned}
$$

Maka transistor cut off, karena arus basis reverse

3). Rangkaian mikrokontroler

Fungsi dari rangkaian mikrokontroller sebagai pengatur kerja output dari rangkaian sistem pengendali penampungan air. Rangkaian ini mengatur kerja output sesuai dengan program yang kita buat. Rangkaian mikrokontroler dapat kita lihat pada gambar 7 dibawah ini :

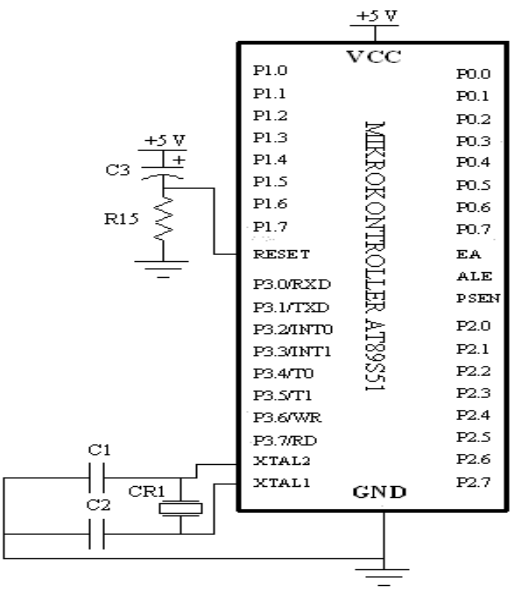

Gambar 7. Rangkaian mikrokontroler 
4). Rangkaian output

Rangkaian output adalah rangkaian yang digunakan untuk menjalankan perintah sesuai program. Rangkaian output terdiri dari rangkaian indicator LED 1, rangkaian indicator LED 2, rangkaian pompa 1, rangkaian pompa 2 dan rangkaian solenoid valve.

a. Rangkaian indikator LED 1

Rangkaian ini berfungsi untuk mengetahui batas level air dalam penampungan air3. Rangkaian ini memiliki 3 warna, diantaranya adalah merah, kuning dan hijau. Rangkaian ini mengelurkan output sesuai dengan perintah dari mikrokontroler dengan input sensor 1, sensor 2, dan sensor 3. Apabila sensor 3 terdeteksi maka LED yang menyala warna merah, sedangkan apabila yang terdeteksi adalah sensor 2 maka LED yang menyala kuning dan merah dan apabila sensor 1 yang terdeteksi maka LED yang menyala merah, kuning dan hijau. Untuk lebih jelasnya gambar rangkaian output LED 1 dapat kita lihat pada gambar 8 dibawah ini :

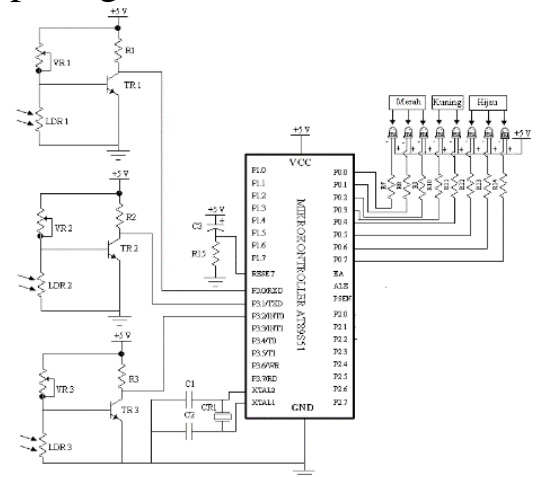

Gambar 8. Rangkaian LED 1 b. Rangkaian indikator LED 2

Rangkaian ini berfungsi sebagai indicator banyaknya pengisian penampungan air yang sudah dijalankan. Sensor 2 adalah sensor yang digunakan untuk mengaktifkan rangkaian LED 2. Pada pengisian pertama air naik hingga sensor 2 terdeteksi maka LED merah akan menyala dan posisi pompa masih menyala hingga air penuh (sensor 1), kemudian ketika air mulai berkurang hingga sampai ke batas sensor 2 maka LED berwarna hijau menyala dan air mengisi lagi hingga sensor 1 sehingga pompa berhenti mengisi, setelah debet air dalam penampungan air berkurang kembali hingga sensor 2 maka LED menyala berwarna kuning dan system pembersihan penampungan dijalankan. Untuk lebih jelasnya rangkaian indicator LED 2 dapat kita lihat pada gambar 9 seperti dibawah ini :

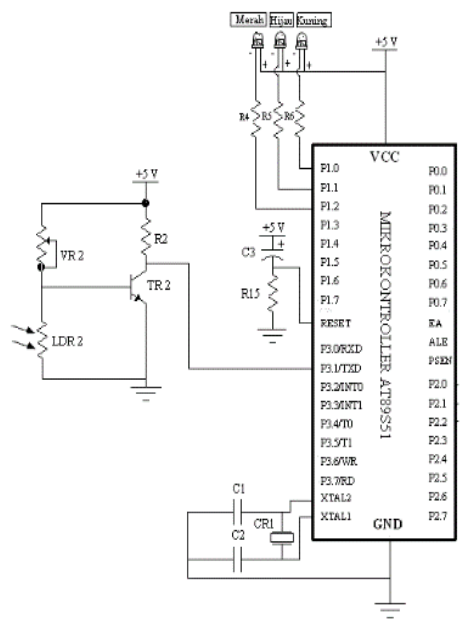

Gambar 9. Rangkaian LED 2 
c. Rangkaian output pompa 1

Rangkaian output pompa 1 pada rangkaian ini berfungsi untuk mengisi air apabila penampungan air terdeteksi bahwa air mencapai level minimum. Rangkaian output pompa 1 dapat kita lihat seperti gambar 10 dibawah ini :

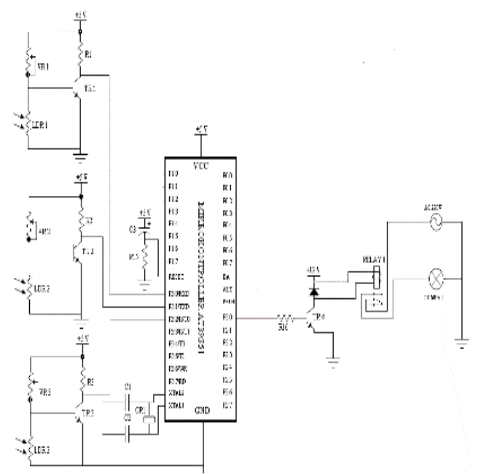

Gambar 10. Rangkaian pompa 1

d. Rangkaian output pompa 2 Rangkaian output pompa 2 berfungsi untuk menjalankan sistem pembuangan air secara otomatis. Rangkaian output pompa 2 dapat kita lihat pada gambar 11 dibawah ini :

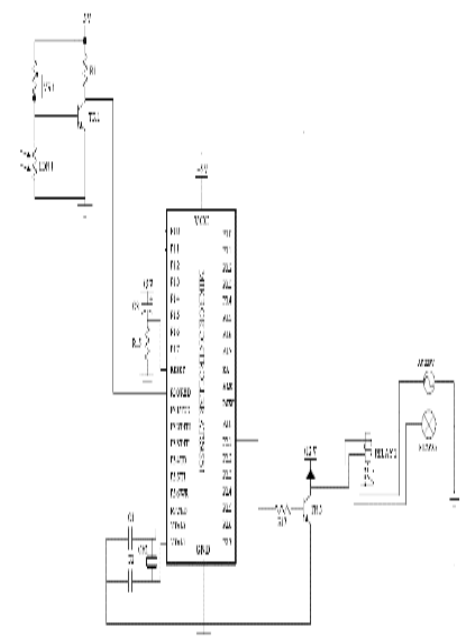

Gambar 11. Rangkaian Pompa 2
1. Rangkaian output solenoid valve

Rangkaian output solenoid valve ini berfungsi untuk memberikan obat pembersih pada penampungan air. Sensor yangh digunakan untuk rangkaiaan ini sensor 3 . Rangkaian output solenoid valve dapat kita lihat pada gambar 12 dibawah ini :

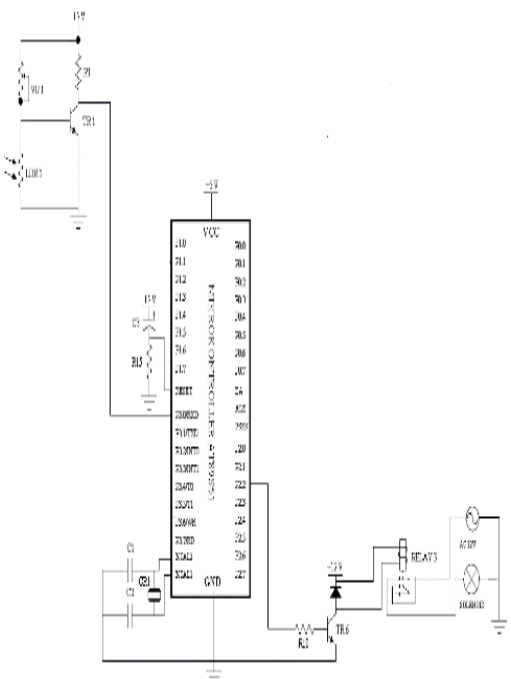

Gambar 12. Rangkaian solenoid valve

Gambar rangkaian keseluruhan rangkaian sistem pengendali penampungan air dalam rumah tangga dengan menggunakan mikrokontroller dapat dilihat pada gambar 1. Sedangkan untuk hasil pengujian alat secara keseluruhan dapat kita lihat pada tabel 1. 


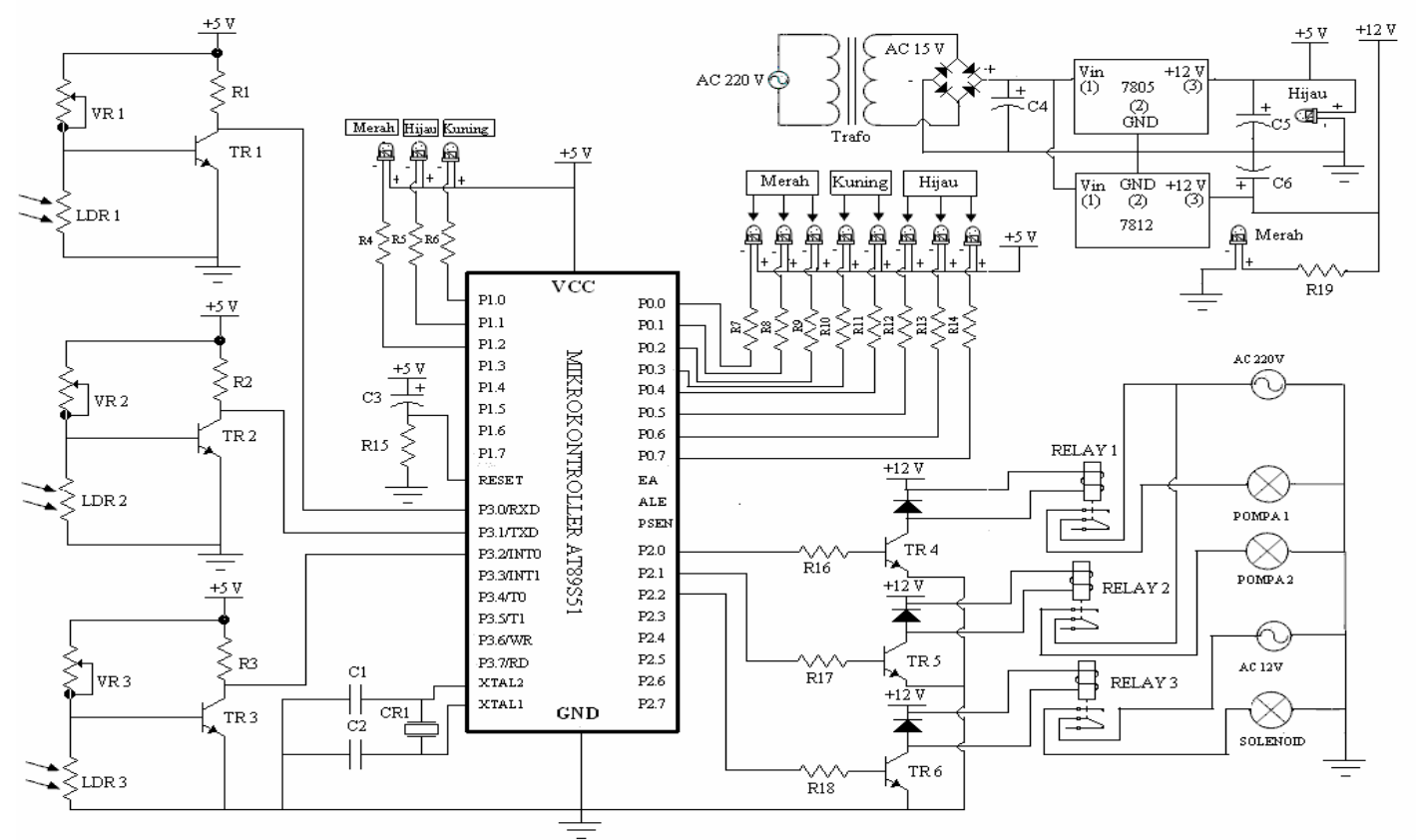

Gambar 13. Gambar keseluruhan rangkaian

Hasil pengujian pada tegangan output dari rangkaian pembagi tegangan ketika LDR tidak terkena cahaya dan terkena cahaya dengan nilai $\mathrm{Rv} 15.5 \mathrm{k} \Omega$ dapat dilihat pada tabel 1. dan untuk hasil keseluruhan dari kerja rangkaian dapat kita lihat pada tabel 2 .

Tabel 1. Hasil pengujian pada tegangan output dari rangkaian pembagi tegangan

\begin{tabular}{|c|c|c|}
\hline \multirow{2}{*}{ Nilai $\mathbf{R v}(\mathbf{k} \mathbf{\Omega})$} & \multicolumn{2}{|c|}{ Keadaan LDR } \\
\cline { 2 - 3 } & Terkena cahaya $(\mathbf{V})$ & Tidak terkena cahaya $(\mathbf{V})$ \\
\hline 15.5 & 0.11 & 4.65 \\
\hline
\end{tabular}

Tabel 2. Hasil keseluruhan dari kerja rangkaian

\begin{tabular}{|c|c|c|c|c|c|c|c|c|c|c|c|c|}
\hline \multirow{3}{*}{$\begin{array}{l}\text { Pengisian } \\
\text { ke }\end{array}$} & \multicolumn{3}{|c|}{ Keadaan } & \multicolumn{6}{|c|}{ Keadaan } & \multicolumn{3}{|c|}{ Keadaan } \\
\hline & \multirow{2}{*}{$\begin{array}{c}\text { Sensor } \\
3\end{array}$} & \multirow{2}{*}{$\begin{array}{c}\text { Sensor } \\
2\end{array}$} & \multirow{2}{*}{$\begin{array}{c}\text { Sensor } \\
1\end{array}$} & \multicolumn{3}{|c|}{ LED 1} & \multicolumn{3}{|c|}{ LED 2} & \multirow{2}{*}{$\begin{array}{c}\text { Pompa } \\
1\end{array}$} & \multirow{2}{*}{$\begin{array}{c}\text { Pompa } \\
2\end{array}$} & \multirow{2}{*}{$\begin{array}{c}\text { Solenoid } \\
\text { valve }\end{array}$} \\
\hline & & & & $\mathbf{M}$ & $\mathbf{K}$ & $\mathbf{H}$ & $\mathbf{M}$ & H & $\mathbf{K}$ & & & \\
\hline \multirow{4}{*}{1} & $\mathrm{TC}$ & TC & $\mathrm{TC}$ & 1 & 0 & 0 & 0 & 0 & 0 & 1 & 0 & 0 \\
\hline & TTC & TC & TC & 1 & 0 & 0 & 0 & 0 & 0 & 1 & 0 & 0 \\
\hline & $\mathrm{TC}$ & TTC & $\mathrm{TC}$ & 1 & 1 & 0 & 1 & 0 & 0 & 1 & 0 & 0 \\
\hline & TC & $\mathrm{TC}$ & TTC & 1 & 1 & 1 & 1 & 0 & 0 & 0 & 0 & 0 \\
\hline \multirow{3}{*}{2} & $\mathrm{TC}$ & TC & $\mathrm{TC}$ & 1 & 1 & 1 & 1 & 0 & 0 & 0 & 0 & 0 \\
\hline & $\mathrm{TC}$ & TTC & TC & 1 & 1 & 0 & 0 & 1 & 0 & 1 & 0 & 0 \\
\hline & TC & TC & TTC & 1 & 1 & 1 & 0 & 1 & 0 & 0 & 0 & 0 \\
\hline \multirow{3}{*}{3} & TC & TC & $\mathrm{TC}$ & 1 & 1 & 1 & 0 & 1 & 0 & 0 & 0 & 0 \\
\hline & $\mathrm{TC}$ & TTC & $\mathrm{TC}$ & 1 & 1 & 0 & 0 & 0 & 1 & 10 & 0 & 0 \\
\hline & TC & $\mathrm{TC}$ & TTC & 1 & 1 & 1 & 0 & 0 & 1 & 0 & 0 & 0 \\
\hline \multirow{3}{*}{4} & TC & $\mathrm{TC}$ & $\mathrm{TC}$ & 1 & 1 & 1 & 0 & 0 & 1 & 0 & 0 & 0 \\
\hline & TC & TTC & $\mathrm{TC}$ & 0 & 0 & 0 & 0 & 0 & 0 & 0 & 0 & 0 \\
\hline & TTC & $\mathrm{TC}$ & $\mathrm{TC}$ & 1 & 0 & 0 & 0 & 0 & 0 & $1^{*}$ & $1 * *$ & $1 * * *$ \\
\hline
\end{tabular}




\begin{tabular}{|l|c|c|c|c|c|c|c|c|c|c|c|c|}
\hline & TC & TTC & TC & 1 & 1 & 0 & 1 & 0 & 0 & 1 & 0 & 0 \\
\cline { 2 - 22 } & TC & TC & TTC & 1 & 1 & 1 & 1 & 0 & 0 & 0 & 0 & 0 \\
\hline
\end{tabular}

Keterangan :

$$
\begin{array}{ll}
\mathrm{M} & =\text { merah } \\
\mathrm{K} & =\text { Kuning } \\
\mathrm{TTC} & =\text { Tidak kena cahaya } \\
0 & =\text { Mati } \\
* * & =\text { Setelah } 10 \text { detik }
\end{array}
$$

\section{SIMPULAN}

\section{A. Simpulan}

Simpulan yang didapat dari hasil didalam proses di atas adalah :

1. Rangkaian ini bekerja dengan menggunakan sensor LDR yang berfungsi untuk menggerakkan pompa 1 sebesar 25 watt yang digunakan untuk mengisi air, pompa 2 sebesar 13 watt yang digunakan untuk membuang air, dan solenoid valve yang fungsinya untuk memberikan obat pembersih pada saat proses pengurasan penampungan air berjalan.

2. Rangkaian ini menjalankan sistem pengisian otomatis hingga tiga kali setelah itu baru menjalankan sistem pengurasan air secara otomatis satu kali. Sistem pembersihan yang dilakukan adalah membuang air selama 10 detik, kemudian air terisi kembali. Setelah 20 detik air mengisi, penampungan air diberi cairan pembersih selama 4 detik dan pompa 1 masih mengisi air hingga level maksimum.

3. Pada rangkaian pembagi tegangan nilai tegangan rata-rata saat kondisi LDR terkena cahaya dari hasil uji adalah 0,11 Volt, sedangkan secara teori nilainya adalah 0,10 Volt.

$$
\begin{aligned}
\mathrm{H} & =\text { Hijau } \\
\mathrm{TC} & =\text { Terkena cahaya } \\
1 & =\text { Nyala } \\
* & =\text { Setelah } 10 \text { menit } \\
* * * & =\text { Setelah } 30 \text { detik }
\end{aligned}
$$

4. Pada rangkaian input nilai tegangan rata-rata saat kondisi

LDR tidak terkena cahaya dari hasil pengujian adalah 4,65 Volt, sedangkan secara teori nilainya adalah 4,55 Volt.

\section{B. Saran}

Penelitian ini masih perlu untuk dikembangkan dan dilakukan penelitian lanjutan. Saran untuk penelitian lanjutan diantaranya adalah

1. Perlu dilakukan penelitian lanjutan untuk kondisi pengisian lebih dari tiga kali dengan menggunakan sistem timer yang dapat diatur waktu pemberian obat pembersih.

2. Diperlukan penelitian pengembangan dengan menambahkan sensor kelembaban dan kekeruhan air untuk mengaktifkan sistem pengurasan

\section{DAFTAR PUSTAKA}

[1] Kadir Abdul, Arduino \& Sensor, Yogyakarta : Andi, 2018

[2] Kadir Abdul, Pemrograman Arduino Menggunakan ArduBlock. Yogyakarta: Andi, 2017

[3] Mada Sanjaya W. S., Ph.D., Panduan Praktis Pemrograman Robot Vision Menggunakan Matlab dan IDE Arduino. Yogyakarta: Andi, 2014 
[4] Budiharto Widodo, DR Perancangan dan Pemrograman Hasta Karya Robot, Andi Yogyakarta, 2013

[5] Tarigan Pernantin, Dasar Teknik Digital. Yogyakarta: Graha Ilmu, 2012

[6] Tim Lab. Mikroprosesor , Mikrokontroller AT89S51 dengan $\mathrm{C} / \mathrm{C}++$ dan Assembler. Yogyakarta: Andi, 2007

[7] Pitowarno Endra, Robotika Desain, Kontrol Dan Kecerdasan Buatan, Yogyakarta: Andi, 2006 